\title{
DNA Catalysts with Tyrosine Kinase Activity
}

\author{
Shannon M. Walsh, Amit Sachdeva, and Scott K. Silverman* \\ Department of Chemistry, University of Illinois at Urbana-Champaign, 600 South Mathews Avenue, Urbana, Illinois 61801, United \\ States
}

Supporting Information

ABSTRACT: We show that DNA catalysts (deoxyribozymes, DNA enzymes) can phosphorylate tyrosine residues of peptides. Using in vitro selection, we identified deoxyribozymes that transfer the $\gamma$-phosphoryl group from a 5'-triphosphorylated donor (a pppRNA oligonucleotide or GTP) to the tyrosine hydroxyl acceptor of a tethered hexapeptide. Tyrosine kinase deoxyribozymes that use pppRNA were identified from each of $\mathrm{N}_{30}, \mathrm{~N}_{40}$, and $\mathrm{N}_{50}$ random-sequence pools. Each deoxyribozyme requires $\mathrm{Zn}^{2+}$, and most additionally require $\mathrm{Mn}^{2+}$. The deoxyribozymes have little or no selectivity for the amino acid identities near the tyrosine, but they are highly selective for phosphorylating tyrosine rather than serine. Analogous GTP-dependent DNA catalysts were identified and found to have apparent $K_{\mathrm{m}}(\mathrm{GTP})$ as low as $\sim 20 \mu \mathrm{M}$. These findings establish that DNA has the fundamental catalytic ability to phosphorylate the tyrosine side chain of a peptide substrate.

A chieving site-specific covalent modification of large protein substrates is a substantial chemical challenge. Important approaches such as native chemical ligation and its variants ${ }^{1}$ enable joining of a small peptide segment (which may be prepared directly via chemical synthesis, incorporating chemical modifications $)^{2}$ to the remainder of a large protein. Nature takes a considerably different approach, using enzymes such as kinases, ${ }^{3}$ glycotransferases, ${ }^{4}$ and many others to perform posttranslational modifications at particular residues of otherwise fully intact proteins. Site-specific modifications of intact proteins are difficult to achieve with small-molecule reagents or catalysts, ${ }^{5}$ and tailoring natural protein enzymes for different functions (e.g., by directed evolution) ${ }^{6}$ is not always feasible. Deoxyribozymes are specific DNA sequences with catalytic activity that have been used to catalyze a variety of reactions, ${ }^{7}$ including self- 5 -phosphorylation. ${ }^{8}$ We have initiated a research program to use deoxyribozymes to perform covalent modification of amino acid side chains in peptide and protein substrates. ${ }^{9}$ In the present study, we report that deoxyribozymes can be identified for phosphorylation of tyrosine residues in tethered peptide substrates, using as the phosphoryl donor either a 5 '-triphosphorylated RNA oligonucleotide (pppRNA) or guanosine $5^{\prime}$-triphosphate (GTP). These findings are a critical first step in the application of deoxyribozymes for practical phosphorylation of larger protein substrates.

We previously reported in vitro selection to identify numerous deoxyribozymes that use pppRNA as a substrate for RNA ligation. ${ }^{10}$ The RNA reacts at the $\alpha$-phosphorus of its
5 '-triphosphate, with departure of pyrophosphate and attachment of the $\alpha$-phosphorus (along with the remainder of the RNA oligonucleotide donor) to the nucleophilic 3'-hydroxyl or $2^{\prime}$-hydroxyl group of the acceptor substrate strand (Figure 1A,

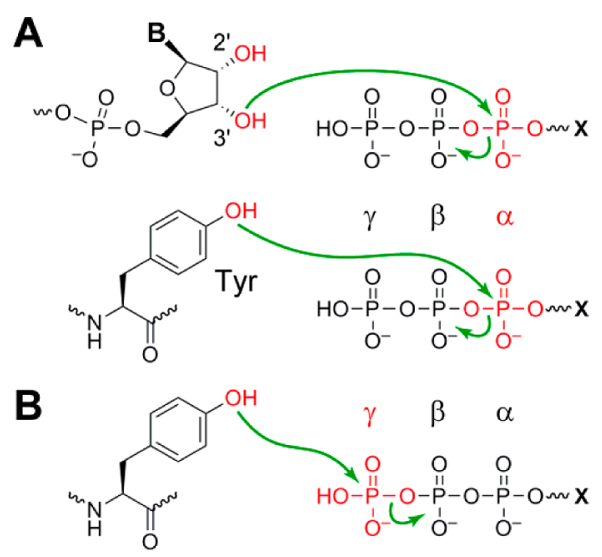

Figure 1. Reactions of phosphoryl donor substrates ( $5^{\prime}$-triphosphorylated RNA or GTP, where X = RNA or G). (A) Reaction of a nucleophile at the $\alpha$-phosphorus, (leaving group = pyrophosphate). In RNA ligation (top), the nucleophile is an RNA hydroxyl group (could also be an internal $2^{\prime}-\mathrm{OH}$ group). In nucleopeptide formation as illustrated with tyrosine (bottom), the nucleophile is an amino acid hydroxyl group. (B) Reaction of a tyrosine nucleophile at the $\gamma$ phosphorus, phosphorylating the tyrosine (leaving group = oligonucleotide 5 '-diphosphate or GDP).

top, $\mathrm{X}=\mathrm{RNA}$ ). Analogously, our efforts on modification of amino acid side chains have used pppRNA to form nucleopeptide linkages with peptide (tyrosine or serine hydroxyl) substrates, again with reaction of the pppRNA at its $\alpha$-phosphorus (Figure 1A, bottom, $\mathrm{X}=\mathrm{RNA}$ ). ${ }^{9}$ In all of these cases, the selection method-which relied upon polyacrylamide gel electrophoresis (PAGE) shift to separate catalytically active DNA sequences-was incapable of identifying deoxyribozymes that catalyze reaction at the $\gamma$-phosphorus of the 5'-triphosphate. This alternative reaction involves departure of the oligonucleotide $5^{\prime}$-diphosphate as the leaving group and transfer of the $\gamma$-phosphoryl group to the nucleophilic amino acid residue (Figure 1B, $\mathrm{X}=\mathrm{RNA}$ ). Presumably, distinct deoxyribozymes that catalyze oligonucleotide phosphorylation were present in our previous selection experiments that identified RNA ligase activity, but the PAGE-

Received: July 23, 2013

Published: September 25, 2013 
shift selection method did not allow such oligonucleotide kinase DNA enzymes to emerge.

Here we have identified deoxyribozymes that achieve phosphorylation of tyrosine ( Tyr, Y) within peptide substrates via the reaction shown in Figure $1 B$, where $X=R N A$ or $G$ for a phosphoryl donor that is, respectively, pppRNA or GTP. For this purpose, we developed a two-stage selection strategy (Figure 2). ${ }^{11}$ As in our previous work, we initially used $5^{\prime}$ -

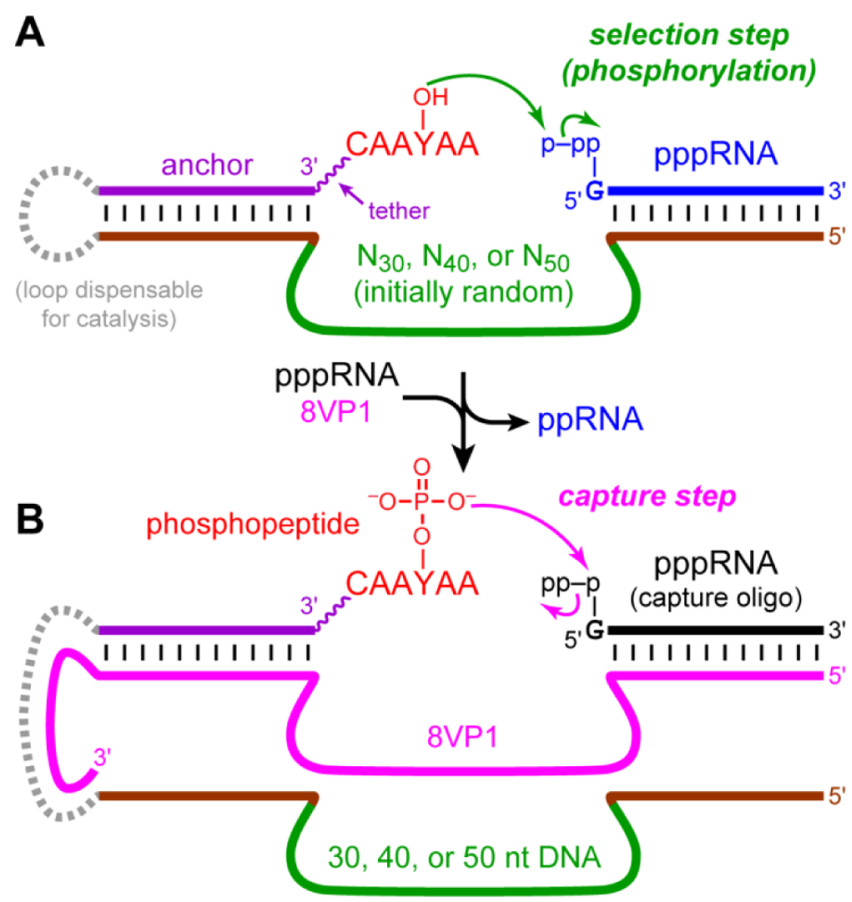

Figure 2. Identifying DNA catalysts with Tyr kinase activity. (A) Key in vitro selection step in which DNA catalyst sequences transfer the $\gamma$ phosphoryl group from pppRNA to the tyrosine hydroxyl group of a tethered peptide. Analogously (not depicted), free GTP can be used as the phosphoryl donor, in which case the remainder of the RNA oligonucleotide is absent. See Figure S1 for structure and synthesis of the peptide substrate and Figure S2 for nucleotide details. (B) Use of 8VP1 as a "capture deoxyribozyme" that selectively attaches an RNA strand to $\mathrm{Tyr}^{\mathrm{P}}$ (phosphorylated) but not $\mathrm{Tyr}^{\mathrm{OH}}$ (unphosphorylated), thereby enabling PAGE-shift separation of DNA catalyst sequences that phosphorylate Tyr.

triphosphorylated RNA as the phosphoryl donor because the RNA oligonucleotide can readily be bound via Watson-Crick base pairs by one of the deoxyribozyme pool's binding arms (Figure 2A). The hexapeptide substrate, CAAYAA, that includes the Tyr acceptor was covalently attached via a disulfide linkage and a hexa(ethylene glycol) [HEG] tether to a DNA anchor oligonucleotide also bound by Watson-Crick interactions to the other pool binding arm. We wished to retain PAGE shift as the physical basis of these selection experiments, because in our hands PAGE shift has been a reliable approach to identify DNA catalysts. ${ }^{9,10}$ However, similar to the situation with oligonucleotide phosphorylation as described above, transfer of a phosphoryl group to the Tyr hydroxyl of the DNA-anchored peptide substrate does not induce a sufficiently large PAGE shift to enable selection. Therefore, we exploited a separate deoxyribozyme that is capable of attaching an RNA strand specifically to phosphorylated tyrosine, $\operatorname{Tyr}^{\mathrm{P}}$, within a peptide substrate (Figure $2 \mathrm{~B}$ ) while discriminating strongly against the unphosphorylated analogue, $\mathrm{Tyr}^{\mathrm{OH}}$. The $8 \mathrm{VP} 1$ deoxyribozyme $^{12}$ was suitable for this purpose with $\sim 40 \%$ capture yield, which is easily sufficient to enable selection. For the present study, we refer to $8 \mathrm{VP} 1$ as a "capture deoxyribozyme", because during the selection process 8VP1 allows us to capture (by PAGE shift) specific DNA catalyst sequences that phosphorylate Tyr.

We recently showed that for DNA-catalyzed nucleopeptide linkage formation, the length of the initially random region is a critical experimental variable. ${ }^{13}$ Therefore, here the initial pool of DNA sequences included either 30, 40, or 50 random nucleotides $\left(\mathrm{N}_{30}, \mathrm{~N}_{40}\right.$, or $\left.\mathrm{N}_{50}\right)$ embedded between two fixedsequence binding arms that enable PCR amplification during each selection round (Figure S2). The selection process, after extensive optimization of the experimental details (see Supporting Information), led to numerous DNA catalysts of all three random-region lengths that transfer the $\gamma$-phosphoryl group of the pppRNA donor to the Tyr acceptor within the DNA-anchored hexapeptide substrate. The key selection step of Figure $2 \mathrm{~A}$ was performed using incubation conditions of 70 $\mathrm{mM}$ HEPES, pH 7.5, $1 \mathrm{mM} \mathrm{ZnCl}, 20 \mathrm{mM} \mathrm{MnCl}_{2}, 40 \mathrm{mM}$ $\mathrm{MgCl}_{2}$, and $150 \mathrm{mM} \mathrm{NaCl}$ at $37{ }^{\circ} \mathrm{C}$ for $14 \mathrm{~h}$. Using these conditions, each of the $\mathrm{N}_{30}, \mathrm{~N}_{40}$, and $\mathrm{N}_{50}$ selection experiments led to robust catalytic activity $(22 \%, 20 \%$, and $27 \%$ yield at rounds 6, 7, and 8, respectively; Figure S3) In contrast, analogous selections with $50 \mathrm{mM}$ CHES, $\mathrm{pH} 9.0,40 \mathrm{mM}$ $\mathrm{MgCl}_{2}$, and $150 \mathrm{mM} \mathrm{NaCl}$ at $37{ }^{\circ} \mathrm{C}$ for $14 \mathrm{~h}$ (omitting $\mathrm{Zn}^{2+}$ and $\mathrm{Mn}^{2+}$ because at $\mathrm{pH} 9.0$ these ions precipitate or oxidize, respectively) led to no activity and were discontinued.

Each of the three successful selection experiments was cloned, and individual deoxyribozymes were characterized. Five, three, and nine unique sequences were identified from the $\mathrm{N}_{30}$, $\mathrm{N}_{40}$, and $\mathrm{N}_{50}$ selections, respectively. Tyr phosphorylation activity was verified by mass spectrometry and 8VP1 reactivity (Table S1). Sequence alignment (Figure S4A) revealed a conserved $11 \mathrm{nt}$ segment at the $5^{\prime}$-end of the initially random region, which is near the $5^{\prime}$-triphosphate of the pppRNA substrate (see Figure 2A). This conservation was observed despite the three different lengths of initially random region; the gaps within the shorter $\mathrm{N}_{30}$ and $\mathrm{N}_{40}$ sequences were located almost exclusively at the $3^{\prime}$-side of the conserved region. For all but one sequence, $k_{\text {obs }}$ values were $0.1-0.5 \mathrm{~h}^{-1}$; the lone exception was the 6CF134 deoxyribozyme from the $\mathrm{N}_{30}$ selection, with higher $k_{\mathrm{obs}}$ of $1.54 \pm 0.22 \mathrm{~h}^{-1}(n=7$; Figure $3 \mathrm{~A})$ The metal ion dependences of the new deoxyribozymes were examined (Figure 3B). Both $\mathrm{Zn}^{2+}$ and $\mathrm{Mn}^{2+}$ were required, whereas $\mathrm{Mg}^{2+}$ was generally dispensable for activity; in a few cases $\mathrm{Mg}^{2+}$ could replace $\mathrm{Mn}^{2+}$, albeit with substantially reduced yield. Again 6CF134 provided the sole exception, requiring only $\mathrm{Zn}^{2+}$ for its catalysis. The deoxyribozymes had slightly different $\mathrm{Zn}^{2+}$ concentration dependence profiles; 0.5 $\mathrm{mM} \mathrm{Zn^{2+ }}$ was highly effective in all tested cases (Figure S7A) and therefore used for all assays. When all new deoxyribozymes except 6CF134 were tested at $\mathrm{pH} 7.0$ (HEPES) or $\mathrm{pH} 6.5$ (MOPS or MES), activity was not detected $(<0.5 \%$; data not shown). In contrast, 6CF134 maintained activity at the lower $\mathrm{pH}$ values, with a linear relationship between $\log \left(k_{\text {obs }}\right)$ and $\mathrm{pH}$ (slope near 1; Figure S8).

The six deoxyribozymes of Figure 3 were assayed with regard to their dependence on peptide sequence, peptide length, and length of the tether connecting the peptide to the DNA anchor oligonucleotide. Each deoxyribozyme was inactive with serine in place of tyrosine at the site of peptide phosphorylation $(<0.5 \%$; data not shown). On the other hand, the 


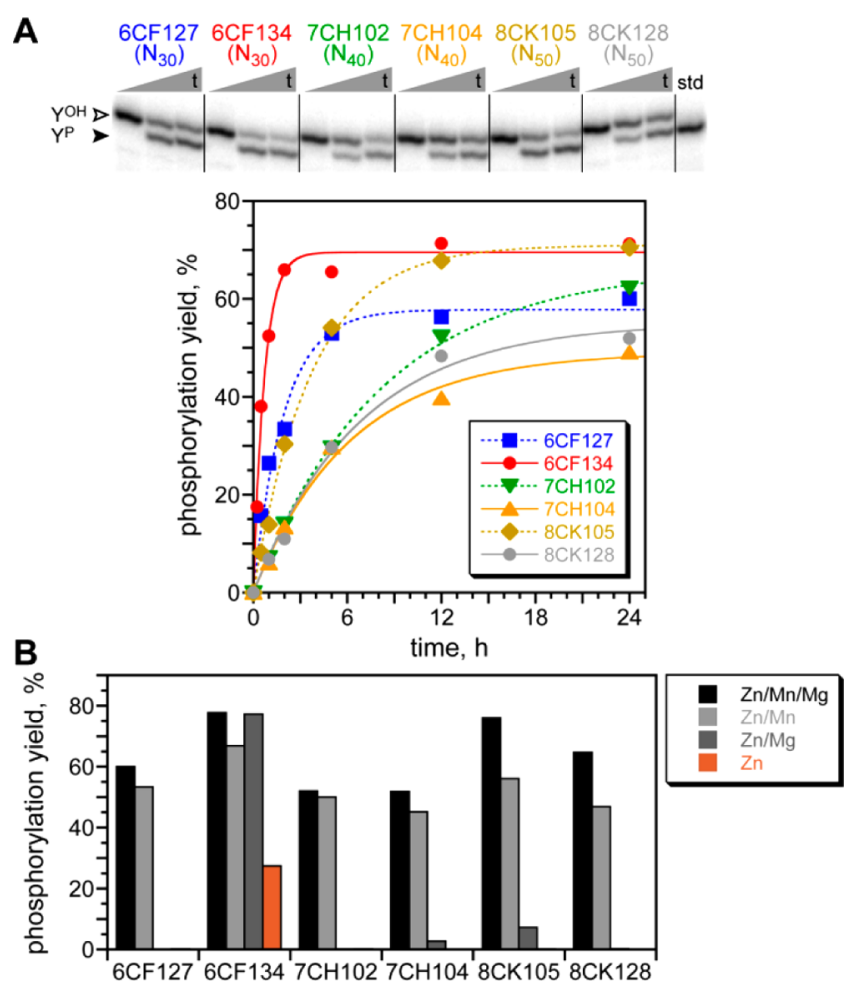

Figure 3. Characterization of individual tyrosine kinase deoxyribozymes that use pppRNA as the phosphoryl donor. All assays were performed in trans, i.e., without the dispensable loop of Figure 2. (A) Kinetic analysis. The PAGE image shows three representative time points $(t=30 \mathrm{~s}, 5 \mathrm{~h}$, and $24 \mathrm{~h})$ for each of six new DNA catalysts. $\mathrm{Y}^{\mathrm{OH}}$ $=$ substrate; $\mathrm{Y}^{\mathrm{P}}=$ product. The kinetic plots are for the same six deoxyribozymes. Incubation conditions: $70 \mathrm{mM}$ HEPES, $\mathrm{pH}$ 7.5, 0.5 $\mathrm{mM} \mathrm{ZnCl}, 20 \mathrm{mM} \mathrm{MnCl}, 40 \mathrm{mM} \mathrm{MgCl}$, and $150 \mathrm{mM} \mathrm{NaCl}$ at 37 ${ }^{\circ} \mathrm{C}$. Kinetic plots for all 17 new deoxyribozymes are in Figure S5. (B) Metal dependence. Each deoxyribozyme was assayed in the presence of the indicated combinations of $0.5 \mathrm{mM} \mathrm{Zn}^{2+}, 20 \mathrm{mM} \mathrm{Mn}^{2+}$, and 40 $\mathrm{mM} \mathrm{Mg}^{2+}$. Shown are time points at $t=24 \mathrm{~h}$; full kinetic plots along with data for the other 11 deoxyribozymes are in Figure S6. The combination $\mathrm{Mn} / \mathrm{Mg}$ had no activity in all cases $(<0.5 \%$; data not shown). Reproducibility of such measurements is conservatively estimated as $\pm 10 \%$ yield.

deoxyribozymes were generally very tolerant of different amino acids at the positions flanking the tyrosine (Figures 4A and S9A). Regarding peptide length, the deoxyribozymes were assayed with the parent HEG-tethered CAAYAA hexapeptide as well as the shorter CYA tripeptide and CY dipeptide (Figures 4B and S9B). All were substantially active with the shorter peptides; in addition, 6CF134 alone was slightly active (albeit with $\sim 100$-fold lower $k_{\text {obs }}$ ) with a nonpeptidic DNA 3 hydroxyl group. Finally, different tether lengths were evaluated. All of the deoxyribozymes performed similarly with a shorter $\mathrm{C}_{3}$ tether in place of the longer HEG tether $(<2$-fold increase in $k_{\mathrm{obs}}$ and $<20 \%$ increase in yield; Figure S10). However, a longer poly(ethylene glycol) tether comprising $10 \mathrm{HEG}$ units did not support detectable catalysis. Consistent with this observation, no activity was observed with an entirely free peptide substrate, i.e., when the hexapeptide substrate was not covalently attached to the DNA anchor oligonucleotide (HPLC assay; data not shown).

Each of the new deoxyribozymes was evaluated for Tyr kinase activity using HEG-tethered CAAYAA and free $1 \mathrm{mM}$ GTP as the phosphoryl donor. In these experiments, GTP was

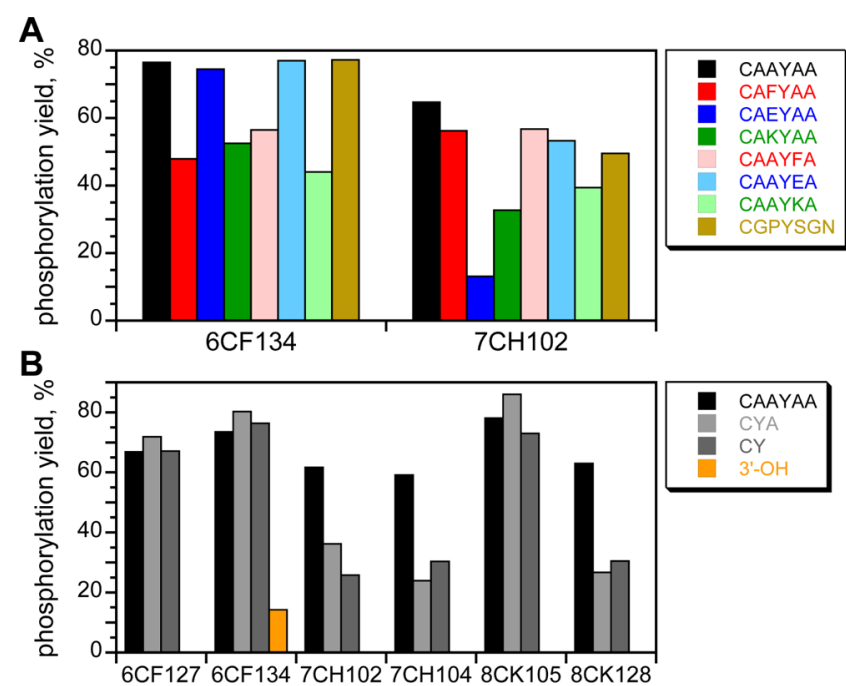

Figure 4. Dependence of the tyrosine kinase deoxyribozymes on peptide sequence and length. All data were acquired using the incubation conditions of Figure 3A. (A) Peptide sequence dependence. The substrate included the indicated peptide on a HEG tether $(t$ $=24 \mathrm{~h}$ ). Two behaviors were observed, represented by 6CF134 and 7CH102; data for the other deoxyribozymes is in Figure S9A. 6CF134 was tolerant of replacing either of the flanking $\mathrm{Ala}(\mathrm{A})$ with any of Phe (F), Glu (E), or Lys (K). 7CH102 was tolerant of all of these substitutions except for Glu to the $\mathrm{N}$-terminal side of the Tyr. (B) Peptide length dependence. The substrate included the indicated peptide on a HEG tether, or the substrate provided only a DNA 3'hydroxyl group for phosphorylation $(t=12 \mathrm{~h})$. Kinetic plots are in Figure S9B.

provided in place of the pppRNA used during selection, which has $\mathrm{G}$ at its 5'-terminus; the remainder of the RNA substrate was included as a separate oligonucleotide. In all cases, no kinase activity was observed (data not shown). Similarly, the $5^{\prime}$ pppGA... of the RNA could not be replaced with any of $5^{\prime}$ pppGGA..., 5'-pppAA..., or 5'-pppA... (data not shown), indicating a particular structural requirement for presentation of the $5^{\prime}$-triphosphate group. We speculate that the conserved 5 -end of the initially random region interacts with the pppRNA donor during catalysis.

In parallel with all of the above efforts, separate new $\mathrm{N}_{30}, \mathrm{~N}_{40}$, and $\mathrm{N}_{50}$ selections were performed in which $1 \mathrm{mM}$ GTP was directly provided in place of pppRNA as the phosphoryl donor for the Tyr hexapeptide acceptor. In these efforts, successful catalysis requires that the initially random DNA region both bind GTP and catalyze phosphoryl transfer, whereas with the pppRNA donor, Watson-Crick binding interactions with the RNA oligonucleotide are preprogrammed. Despite this increased challenge, DNA catalysts emerged from each of the pools, with $5 \%, 6 \%$, and $8 \%$ yield at rounds 8,21 , and 16 for $\mathrm{N}_{30}, \mathrm{~N}_{40}$, and $\mathrm{N}_{50}$, respectively (Figure S3). Cloning revealed a single sequence from each selection, unrelated to each other and to the pppRNA-dependent DNA catalysts (Figure S4B). The $\mathrm{N}_{30}$ and $\mathrm{N}_{50}$ deoxyribozymes, 8EA101 and 16EC103, each had substantial catalytic activity, with $k_{\text {obs }}=0.2 \mathrm{~h}^{-1}$ and yields as high as $45 \%$ (Figure 5). The $\mathrm{N}_{40}$ deoxyribozyme, 21EB121, had more modest $5 \%$ yield and was not examined further (data not shown). Kinase activity was verified by mass spectrometry and 8VP1 reactivity (Table S1). At $\mathrm{pH} 7.5$ and $37{ }^{\circ} \mathrm{C}$ in the presence of $0.5 \mathrm{mM} \mathrm{Zn}^{2+}, 20 \mathrm{mM} \mathrm{Mn}{ }^{2+}, 40 \mathrm{mM} \mathrm{Mg}^{2+}$, and 150 $\mathrm{mM} \mathrm{Na}{ }^{+}$, each of 8EA101 and 16EC103 had a substantial GTP concentration dependence, with apparent $K_{\mathrm{m}}(\mathrm{GTP})$ values of 

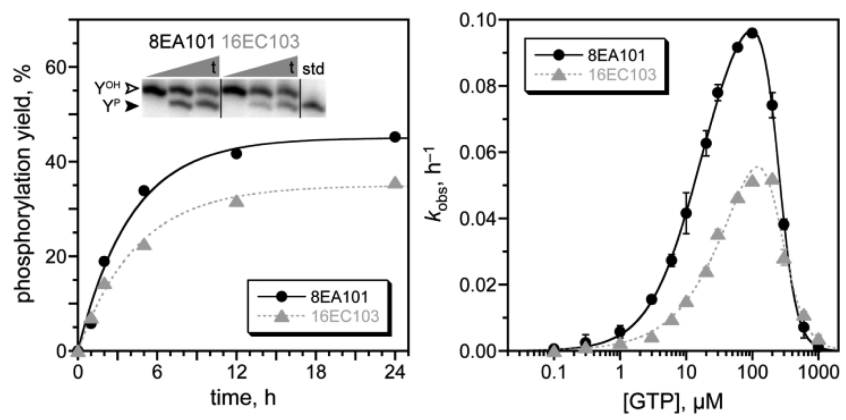

Figure 5. Activities of $8 \mathrm{EA} 101$ and $16 \mathrm{EC} 103$, the $\mathrm{N}_{30}$ and $\mathrm{N}_{50}$ deoxyribozymes that use free GTP as the phosphoryl donor for Tyr phosphorylation. Kinetic analysis as in Figure $3\left(+100 \mu \mathrm{M}\right.$ GTP). $k_{\mathrm{obs}}$ values $(n=3)$ : 8EA101 $0.23 \pm 0.01$ and 16EC103 $0.23 \pm 0.04 \mathrm{~h}^{-1}$. See Figure S11 for details of the apparent $K_{\mathrm{m}}$ analysis, which used initialrate kinetics $(0-2 \mathrm{~h})$.

$\sim 20$ and $42 \mu \mathrm{M}$, respectively, as well as substantial inhibition above 100-200 $\mu \mathrm{M}$ GTP (Figure S11). These apparent $K_{\mathrm{m}}$ values are similar to (or better than) those for many natural protein kinases with ATP. ${ }^{14}$ 8EA101 and 16EC103 had optimal $\mathrm{Zn}^{2+}$ concentrations of $0.3-0.5 \mathrm{mM}$ in the presence of $\mathrm{Mn}^{2+}$, $\mathrm{Mg}^{2+}$, and $100 \mu \mathrm{M}$ GTP (Figure S7B) and were inhibited when $[\mathrm{GTP}]>100 \mu \mathrm{M}$. The identification of 8EA101 and 16EC103 establishes that DNA-catalyzed Tyr phosphorylation activity is not restricted to a pppRNA phosphoryl donor that is bound by predetermined Watson-Crick interactions. Instead, $\mathrm{N}_{30}-\mathrm{N}_{50}$ DNA sequences can simultaneously support both high-affinity GTP binding and phosphoryl transfer catalytic function.

In summary, we have shown that DNA can have tyrosine kinase activity, using either pppRNA or GTP as the phosphoryl donor. Along with our recent report on DNA-catalyzed dephosphorylation, ${ }^{15}$ these observations expand DNA catalysis to include important regulatory post-translational modifications. Many challenges remain in these efforts. Mechanistic studies of all of these deoxyribozymes are desirable, although without high-resolution structural information yet available for any deoxyribozyme of any kind, ${ }^{16}$ such studies are a longerterm objective. Our continuing efforts pursue tyrosine kinase deoxyribozymes with peptide sequence selectivity, improved reactivity of small-molecule phosphoryl donors (including via integration of an intact NTP aptamer domain near the random region), and DNA-catalyzed phosphorylation of free peptide and protein substrates.

\section{ASSOCIATED CONTENT}

\section{S Supporting Information}

Experimental details and additional data. This material is available free of charge via the Internet at http://pubs.acs.org.

\section{AUTHOR INFORMATION}

\section{Corresponding Author}

scott@scs.illinois.edu

Notes

The authors declare no competing financial interest.

\section{ACKNOWLEDGMENTS}

This research was supported by grants to S.K.S. from the National Institutes of Health (R01GM065966), the Defense Threat Reduction Agency (HDTRA1-09-1-0011), and the
National Science Foundation (CHE0842534). A.S. was partially supported by NIH T32 GM070421.

\section{REFERENCES}

(1) Kent, S. B. H. Chem. Soc. Rev. 2009, 38, 338.

(2) Szewczuk, L. M.; Tarrant, M. K.; Cole, P. A. Methods Enzymol. 2009, 462, 1.

(3) (a) Manning, G.; Whyte, D. B.; Martinez, R.; Hunter, T.; Sudarsanam, S. Science 2002, 298, 1912. (b) Tarrant, M. K.; Cole, P. A. Annu. Rev. Biochem. 2009, 78, 797. (c) Graves, L. M.; Duncan, J. S.; Whittle, M. C.; Johnson, G. L. Biochem. J. 2013, 450, 1.

(4) Thibodeaux, C. J.; Melancon, C. E.; Liu, H. W. Nature 2007, 446, 1008.

(5) Stephanopoulos, N.; Francis, M. B. Nat. Chem. Biol. 2011, 7, 876.

(6) (a) Goldsmith, M.; Tawfik, D. S. Curr. Opin. Struct. Biol. 2012, 22, 406. (b) Cobb, R. E.; Si, T.; Zhao, H. Curr. Opin. Chem. Biol. 2012, $16,285$.

(7) (a) Silverman, S. K. Chem. Commun. 2008, 3467. (b) Schlosser, K.; Li, Y. Chem. Biol. 2009, 16, 311. (c) Silverman, S. K. Angew. Chem., Int. Ed. 2010, 49, 7180.

(8) (a) Li, Y.; Breaker, R. R. Proc. Natl. Acad. Sci. U.S.A. 1999, 96, 2746. (b) Wang, W.; Billen, L. P.; Li, Y. Chem. Biol. 2002, 9, 507. (c) Achenbach, J. C.; Jeffries, G. A.; McManus, S. A.; Billen, L. P.; Li, Y. Biochemistry 2005, 44, 3765. (d) McManus, S. A.; Li, Y. Biochemistry 2007, 46, 2198. (e) McManus, S. A.; Li, Y. J. Mol. Biol. 2008, 375, 960. (f) McManus, S. A.; Li, Y. J. Am. Chem. Soc. 2013, 135, 7181.

(9) (a) Pradeepkumar, P. I.; Höbartner, C.; Baum, D. A.; Silverman, S. K. Angew. Chem., Int. Ed. 2008, 47, 1753. (b) Sachdeva, A.; Silverman, S. K. Chem. Commun. 2010, 46, 2215. (c) Wong, O.; Pradeepkumar, P. I.; Silverman, S. K. Biochemistry 2011, 50, 4741.

(10) (a) Silverman, S. K. Acc. Chem. Res. 2009, 42, 1521. (b) FlynnCharlebois, A.; Wang, Y.; Prior, T. K.; Rashid, I.; Hoadley, K. A.; Coppins, R. L.; Wolf, A. C.; Silverman, S. K. J. Am. Chem. Soc. 2003, 125, 2444. (c) Wang, Y.; Silverman, S. K. J. Am. Chem. Soc. 2003, 125, 6880.

(11) In related efforts, we attempted to select for transfer to Tyr of the $\gamma$-thiophosphoryl group from ATP $\gamma \mathrm{S}$, GTP $\gamma \mathrm{S}$, or $5^{\prime}-\gamma$-thiotriphosphorylated RNA using APM $\left(\mathrm{Hg}^{2+}\right)$ gels: Saran, D.; Nickens, D. G.; Burke, D. H. Biochemistry 2005, 44, 15007. Biondi, E.; Burke, D. H. Methods Mol. Biol. 2012, 883, 111. However, these experiments were unsuccessful.

(12) Sachdeva, A.; Chandra, M.; Chandrasekar, J.; Silverman, S. K. ChemBioChem 2012, 13, 654.

(13) Velez, T. E.; Singh, J.; Xiao, Y.; Allen, E. C.; Wong, O.; Chandra, M.; Kwon, S. C.; Silverman, S. K. ACS Comb. Sci. 2012, 14, 680.

(14) Becher, I.; Savitski, M. M.; Savitski, M. F.; Hopf, C.; Bantscheff, M.; Drewes, G. ACS Chem. Biol. 2013, 8, 599.

(15) Chandrasekar, J.; Silverman, S. K. Proc. Natl. Acad. Sci. U.S.A. 2013, 110, 5315.

(16) Nowakowski, J.; Shim, P. J.; Prasad, G. S.; Stout, C. D.; Joyce, G. F. Nat. Struct. Biol. 1999, 6, 151. 